\title{
Mathematics Achievement Gaps Between Suburban Students and Their Rural and Urban Peers Increase Over Time
}

\author{
SUZANNE E. GRAHAM AND LAUREN E. PROVOST
}

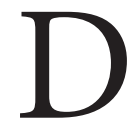
eveloping strong mathematical skills early in life is necessary for all students. ${ }^{1}$ At the most basic level, an understanding of mathematics is necessary for citizens to evaluate major financial decisions (such as whether to buy a house or take a job), plan a family budget, and understand political polls. Mathematics also helps students develop general problem-solving skills. Furthermore, without a strong foundation in early mathematics, students are not prepared to enroll in more advanced mathematics courses at the high school and college level. ${ }^{2}$ Mathematics courses such as algebra, geometry, statistics, and calculus provide an essential foundation not only for careers in science, technology, engineering, and mathematics (STEM) fields, but also in social science research, business, and accounting, for example.

Rural schools, however, do not always have access to the same level of federal funding as urban and suburban schools, which can limit the opportunity students have for learning mathematics. ${ }^{3}$ Nine percent of rural school district budgets are covered by federal funds, compared with 11 percent of budgets in urban school districts. ${ }^{4}$ Low salaries, threats of consolidation, and the geographic isolation of many rural areas make it a challenge for rural districts to attract and retain highly qualified teachers, particularly in high-need subjects such as mathematics. ${ }^{5}$ Despite these challenges, many rural schools offer unique factors that are associated with mathematics achievement, such as smaller class size and community cohesiveness. ${ }^{6}$

In this brief, we consider whether attending a school in a rural, urban, or suburban community is related to children's mathematics achievement in kindergarten, and whether increases in mathematics achievement between kindergarten

\section{Key Findings}

- Rural and urban kindergarten students have slightly lower average mathematics achievement levels than their suburban peers.

- The average increase in mathematics achievement from kindergarten to eighth grade for rural and urban children is smaller than the increase for suburban children, resulting in a widening achievement gap over time.

- Average differences in mathematics achievement favoring suburban children exist in the Northeast, South, and Midwest, but not in the West.

- Average achievement differences between rural, urban, and suburban students are larger for Asian and Native-American students than for white, African-American, and Hispanic students.

- Family socioeconomic status explains much, but not all, of the observed differences in average mathematics achievement levels of rural, urban, and suburban children.

and eighth grade differ for children in rural, urban, and suburban schools. We also consider whether achievement differs by region of the country and for children of different racial and ethnic groups. Finally, we examine the impact of a family's socioeconomic status, and the ways in which place and socioeconomic status together affect both early mathematics achievement levels and change over time. 
Mathematics Achievement in Kindergarten Is Lower for Rural and Urban Children and the Achievement Gap Widens by Eighth Grade

The mathematics achievement score of an average rural kindergartener is 34 (on a scale from 0 to 174 correct). ${ }^{7}$ This is approximately two points lower than the score of an average suburban student. The average urban student's mathematics achievement score is 33 .

Although these scores seem low and the differences small, the assessment is designed to measure mathematics achievement on a common metric for students across a wide span of grades (kindergarten through grade 8). Therefore kindergarten students will typically score in the lower end of the distribution. Eighty percent of kindergarten children answer between 22 and 49 items correctly; thus, a seemingly small average difference of two to three points can indicate a meaningful difference in achievement. ${ }^{8}$

As shown in Table 1, deficits in the average achievement levels of rural and urban students compared with their suburban peers grow between kindergarten and eighth grade. By eighth grade, the difference in average mathematics achievement levels of rural and suburban students has more than tripled, and the average difference between urban and suburban students has doubled. Of course, in eighth grade students are more likely to score in the higher end of the possible range, with 80 percent of eighth graders answering between 108 and 166 items correctly. ${ }^{9}$ There is also a broader range of scores in eighth grade. Nonetheless, while both rural and urban students fare less well over time than their suburban counterparts, rural students fall farthest behind.

Table 1. AVERAge mathematics aChieVEment in KINDERGARTEN AND EIGHTH GRADE

\begin{tabular}{lccc}
\hline Location & Kindergarten & $\begin{array}{c}\text { Grade } \\
\text { Eight }\end{array}$ & $\begin{array}{c}\text { Achievement } \\
\text { Gain }\end{array}$ \\
\hline Rural & 34 & 134 & 100 \\
Urban & 33 & 135 & 102 \\
Suburban & 36 & 141 & 105 \\
Rural-suburban difference & -2 & -7 & -5 \\
Urban-suburban difference & -3 & -6 & -3 \\
\hline
\end{tabular}

Note: The sample size is 15,260 in kindergarten and 7,216 in eighth grade. The analysis was conducted using weights appropriate for the complex survey sampling design of the Early Childhood Longitudinal Study. All values have been rounded to the nearest whole number. All differences are statistically significant $(p<0.001)$.
The differences in the average observed mathematics achievement levels reported in Table 1 may be underestimated because large frequencies of students score at the lower end of the mathematics achievement scale in kindergarten (a floor effect) and at the higher end of the achievement scale in eighth grade (a ceiling effect). These floor and ceiling effects limit variability in mathematics achievement in the lower end of the distribution for kindergarten students and in the upper end of the distribution for eighth grade students, potentially limiting the magnitude of change in achievement between kindergarten and eighth grade. Furthermore, the kindergarten floor effect is more pronounced for rural and urban students than for suburban students. That is, there is a larger concentration of students scoring in the lower end of the distribution. For example, while only one-half of suburban students score below 37 points, approximately two-thirds of the rural and urban students score less than 37 points. The eighth grade ceiling effect, in contrast, is more pronounced for suburban children. Although 50 percent of suburban children score higher than 149 points, fewer than 40 percent of the rural and urban children do so.

\section{Mathematics Achievement Learning Curves}

Average mathematics achievement scores in kindergarten and eighth grade only tell part of the story. It is also important to understand the learning curves children follow in the development of mathematics achievement. The curves presented in Figure 1 display predicted growth in mathematics achievement between kindergarten and eighth grade for average rural, urban, and suburban students. ${ }^{10}$ The overall shape of the curves indicates that the average yearly improvement in mathematics achievement during elementary school and middle school is not constant over time. Instead, elementary school sees rapid increases in skills, which level off between Grades 5 and 8. Given the ceiling effects described above, this leveling off may be overstated; that is, the assessment may underestimate the true increases in mathematics achievement by eighth grade.

Comparing the three curves in Figure 1 reveals that, although the general trajectory is the same for the three groups, the overall slope is steeper for suburban children than for rural and urban children. This reflects larger increases in mathematics achievement over time for suburban children than for rural and urban children, whose growth curves are practically indistinguishable. 
Figure 1. Predicted aVerage Change Curves in matheMATICS ACHIEVEMENT BETWEEN KINDERGARTEN AND EIGHTH GRADE FOR RURAL, URBAN, AND SUBURBAN CHILDREN

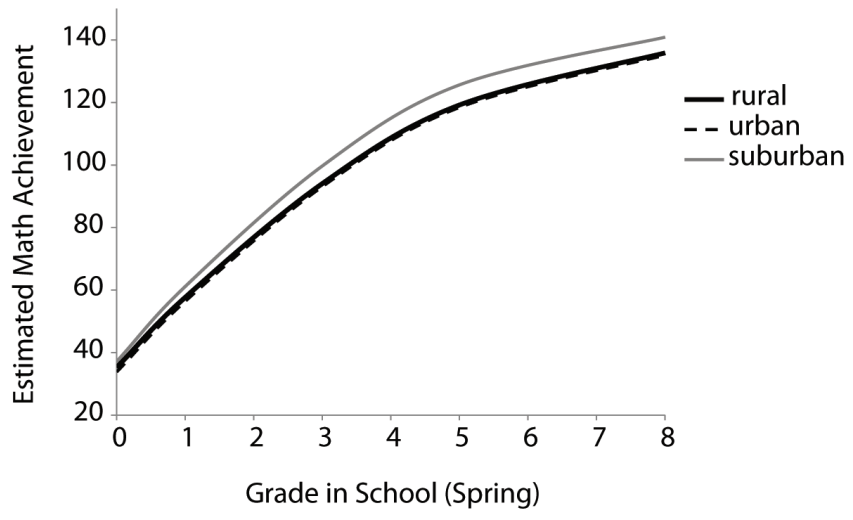

Differences in Achievement Trajectories by Place and Region

Of course, not all rural, urban, and suburban communities are the same. In particular, characteristics of these communities differ by different regions in the United States. Therefore it is not surprising to learn that differences in average rural, urban, and suburban mathematics achievement trajectories differ by geographic region.

Figure 2 compares predicted mathematics achievement growth curves of rural, urban, and suburban children across the four major regions in the United States. In the Northeast, South, and Midwest, predicted achievement curves for average suburban children (represented by the solid grey lines) are consistently higher than those of urban and rural children (represented by the dashed black and solid black lines, respectively). However, magnitudes of the suburban/ rural/urban differences in achievement are not the same

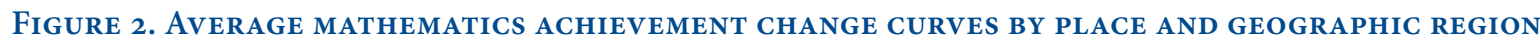

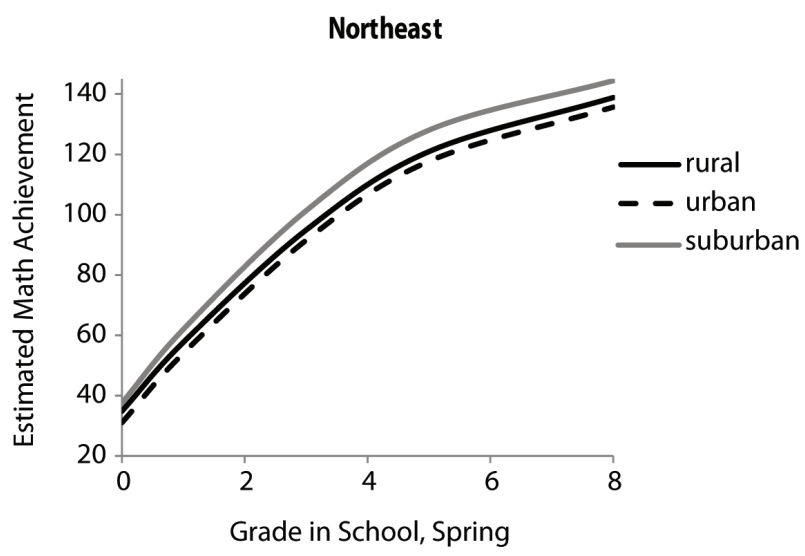

Midwest

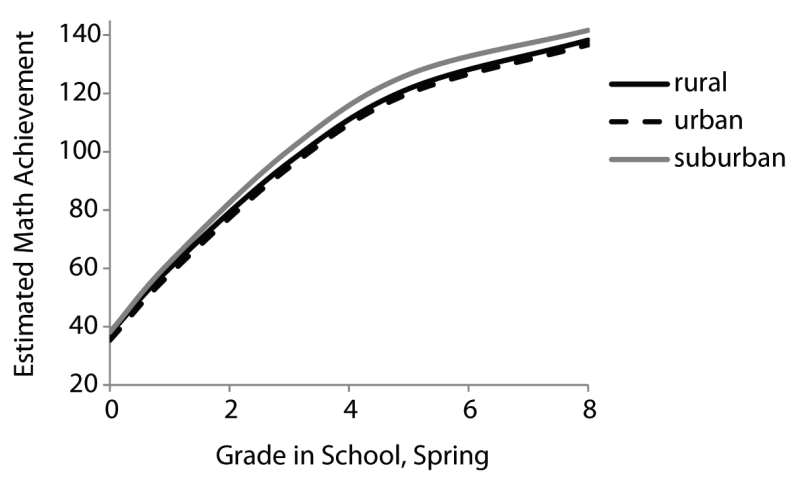

South

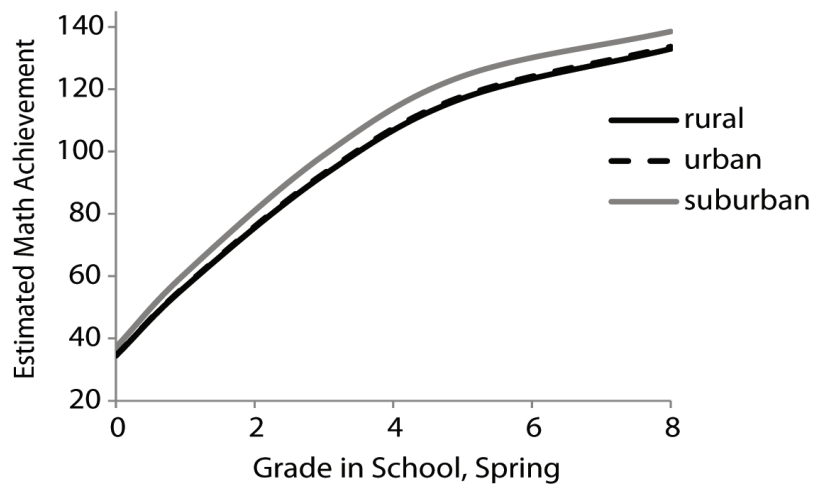

West

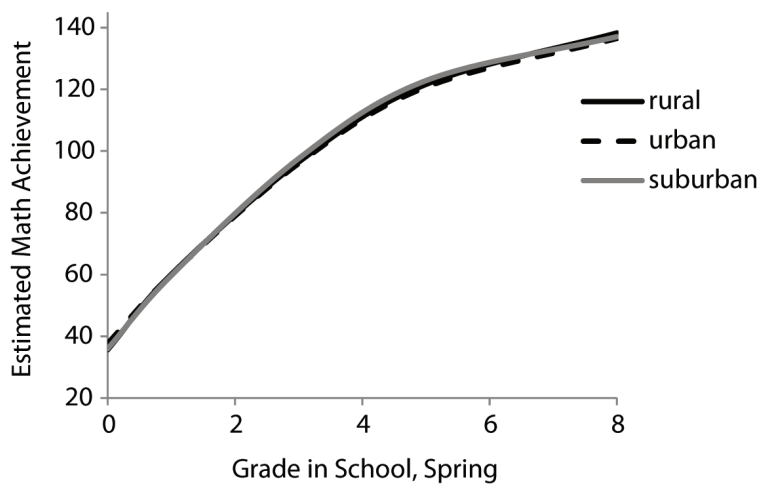


across regions. For example, in the Northeast, the average urban child's growth curve is slightly lower than that of the average rural child, but in the South and the Midwest, there is essentially no difference in average mathematics achievement of rural and urban children. Interestingly, in the West, the average achievement curves for rural, urban, and suburban children do not differ.

Figure 3. Predicted average Change curves IN MATHEMATICS ACHIEVEMENT FOR CHILDREN OF DIFFERENT RACIAL AND ETHNIC BACKGROUNDS

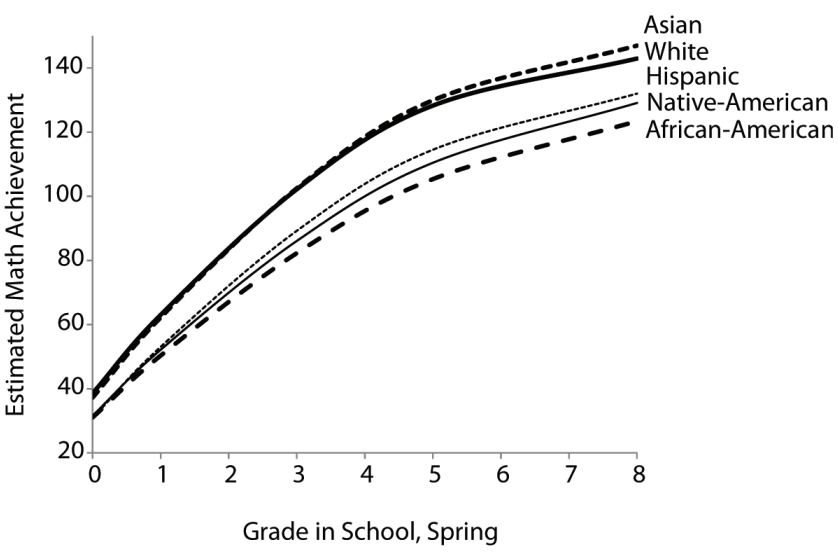

\section{Effects of Place Differ by Race-Ethnicity}

Mathematics achievement gaps between white and non-white students are well-documented, and the story is no different here. As Figure 3 shows, predicted mathematics achievement growth curves for children of different racial and ethnic backgrounds are markedly different. Not unexpectedly, white and Asian children have similar predicted growth curves, while the trajectories are substantially lower for children who are Hispanic, African American, or Native American.

These general differences in average achievement levels by race and ethnicity are also apparent across place and region. However, achievement differences of rural, urban, and suburban children are not the same across racial and ethnic groups, as shown in Figure $4 .{ }^{11}$ Differences by place (rural, urban, or suburban) are identical across regions so the descriptions that follow are relevant to all regions.

The top two graphs compare average rural, suburban, and urban white and African-American students from the South. It is evident that the average African-American student is predicted to score substantially lower on mathematics assessments at all points in time than the average white student.
Comparing growth curves within racial groups, both white and African-American students from rural areas achieve at lower levels than their peers in urban and suburban places.

Similar differences by place are evident for Asian students. Mathematics achievement levels for rural Asian students are predicted to be lower than those of urban and suburban students. However, the estimated difference between rural and non-rural Asian students is approximately 50 percent greater than the rural/non-rural average achievement difference for white and AfricanAmerican students.

Finally, for Hispanic and Native-American students, the predicted average growth curves for urban and rural students are lower than those for suburban students. Particularly noteworthy is the magnitude of the difference between suburban and urban/rural Native-American students. The average suburban Native-American is predicted to have achievement levels that are approximately 7 points higher than rural and urban students in kindergarten and nearly 18 points higher by fifth grade. (Due to the relatively small number of Native-American students in the original sample and student attrition between kindergarten and eighth grade, the curves in this plot extend only through fifth grade.)

\section{Family Socioeconomic Background Explains Some but Not All Rural, Urban, and Suburban Differences in Mathematics Growth Curves}

Prior research has found that students from families of higher socioeconomic status tend to score higher on mathematics assessments. ${ }^{12}$ As is shown in Figure 5, there are also substantial effects of a child's socioeconomic background on the rate of change in mathematics achievement between kindergarten and eighth grade. The solid gray line represents the predicted growth in achievement over time for a child from an affluent family (here defined as the $90^{\text {th }}$ percentile of the socioeconomic status distribution), while the black dashed line represents a child from a disadvantaged background ( $10^{\text {th }}$ percentile). The middle line predicts achievement growth of a child of average socioeconomic status. As the curves indicate, a kindergartener from an affluent family is predicted to score highest on mathematics and enjoy a more rapid increase in mathematics achievement over time than the other children, resulting in a substantial achievement gap by eighth grade. 


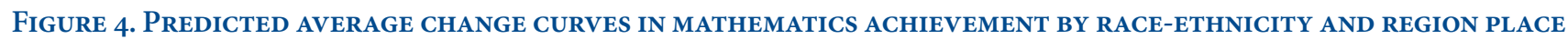

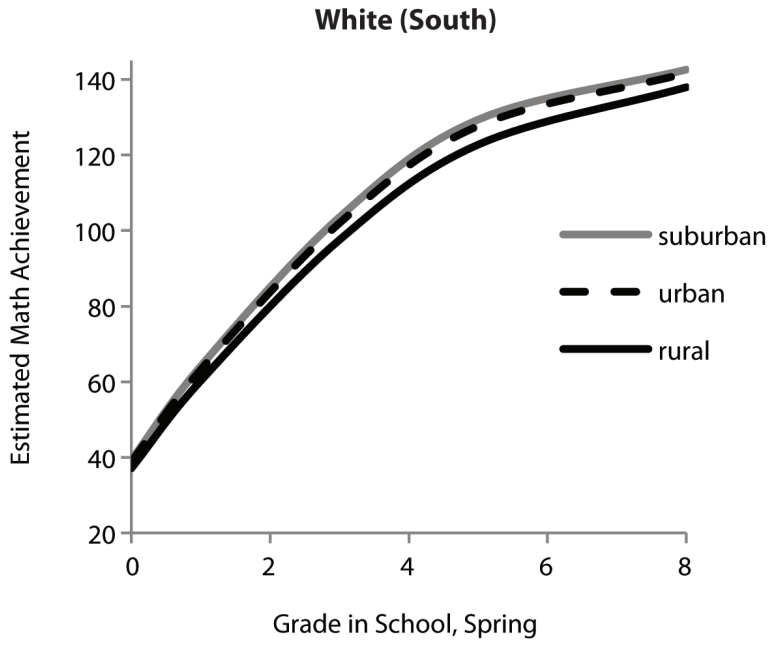

Hispanic (West)

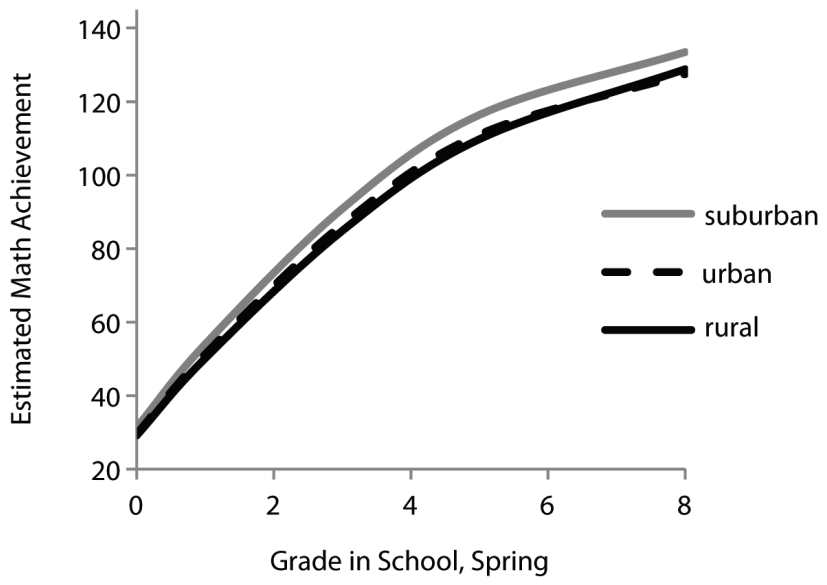

Native-American (Midwest)

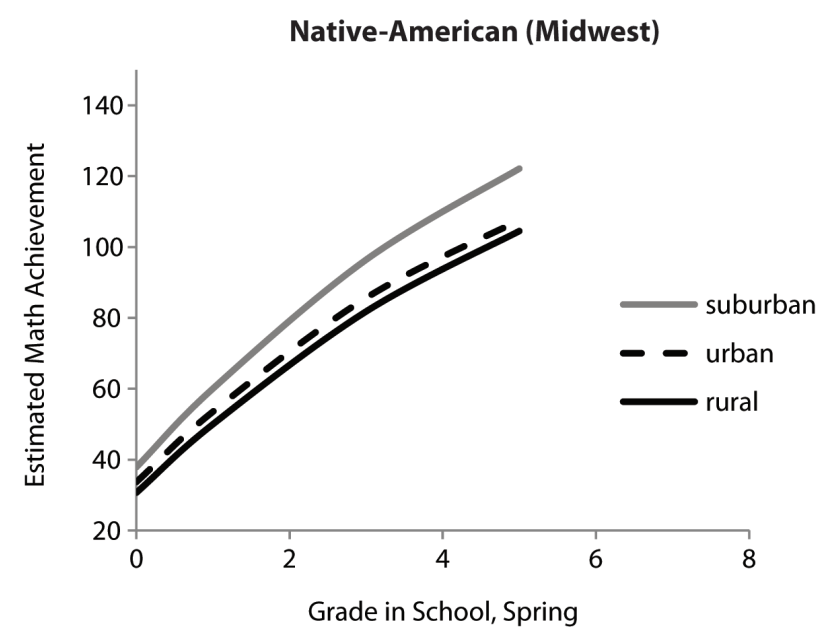

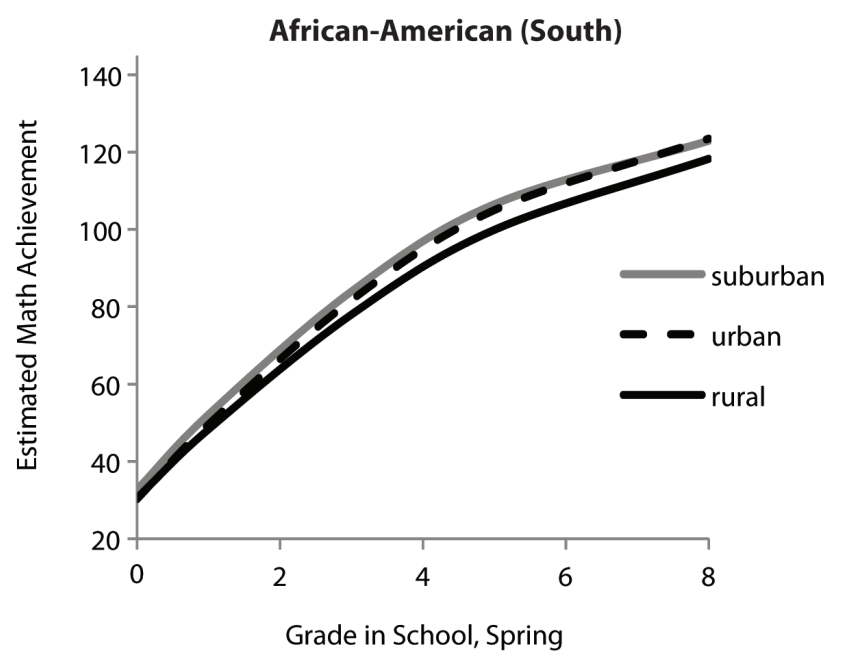

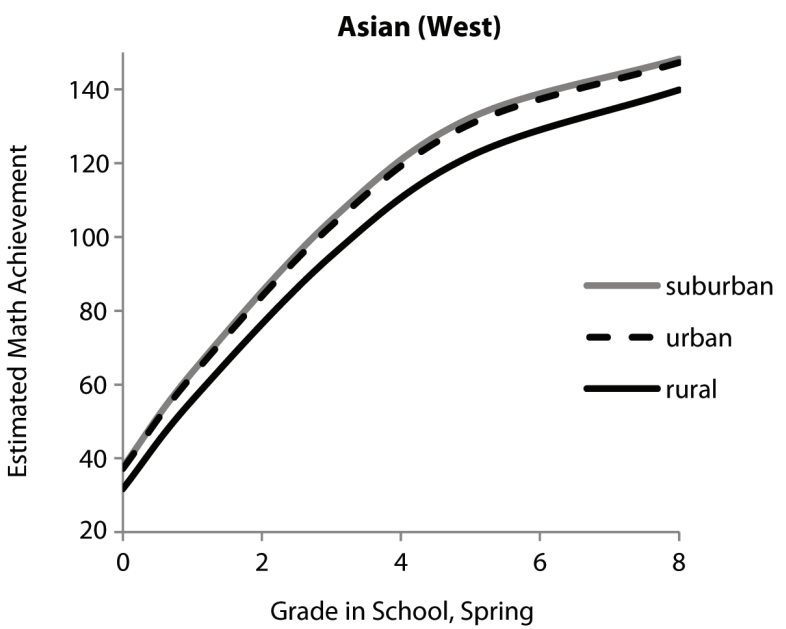


Figure 5. Predicted average Change Curves FOR CHILDREN FROM FAMILIES OF HIGH AND LOW SOCIOECONOMIC BACKGROUNDS

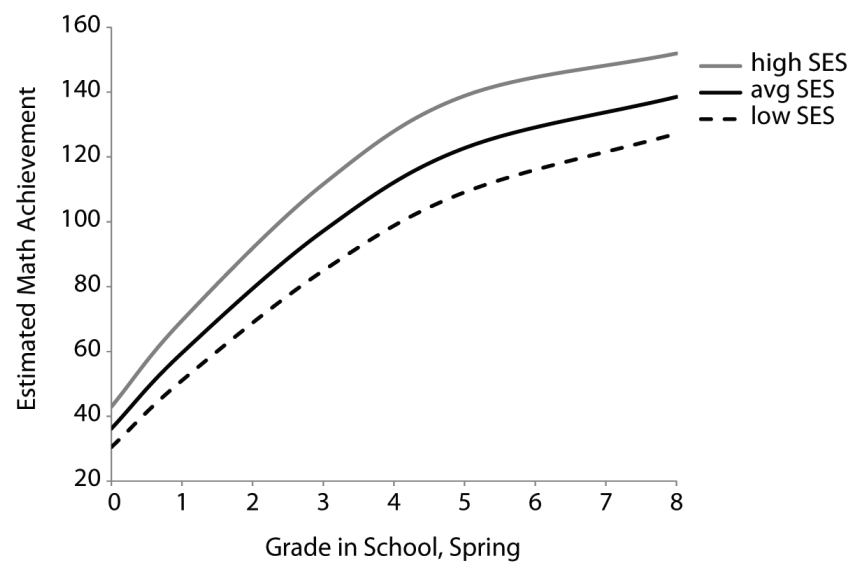

Not surprisingly, we find that achievement differences by place are smaller, although still statistically significant, when we compare children from similar socioeconomic backgrounds. For example, the predicted difference in average fifth grade achievement levels of rural and suburban white, African-American, and Hispanic children is approximately 7 points before taking socioeconomic background into account and 3 points when comparing children of similar socioeconomic status. Larger differences in mathematics achievement by place are evident for Asian and Native-American students, even after taking socioeconomic background into account. For Asian students, even though there is little difference in average achievement between urban and suburban students, rural students of similar socioeconomic backgrounds score approximately 5 points lower. The mathematics achievement scores of average Native-American suburban fifth graders are approximately 12 points higher than the average urban or rural student of similar socioeconomic status.

\section{Conclusion}

Why do rural children from lower socioeconomic families start kindergarten with lower mathematics achievement and make less progress during elementary and middle school? In concluding, we consider just a few of the possible reasons for this distinction.

Students whose parents are more educated tend to do better on measures of academic achievement, ${ }^{13}$ and parent education levels tend to be lower in rural than urban and suburban communities. ${ }^{14}$ In addition, a larger proportion of rural students (42 percent) have parents who do not expect them to complete a bachelor's degree. This compares with 30 percent of urban and 25 percent of suburban students. ${ }^{15}$
Another source of rural difference in mathematics achievement scores starts before kindergarten. Rural children are less likely than suburban and urban children to attend preschool. In 2005, approximately half of children aged 3-5 in rural areas attended a center-based preprimary program (that is, day care center, Head Start program, preschool, or nursery school), while nearly 60 percent of children in urban and suburban communities attended such programs. ${ }^{16}$

In addition, schools in rural communities tend to have fewer resources available than schools in urban and suburban communities. Consequently, rural teachers have lower average salaries than their urban and suburban counterparts, making it difficult for many rural schools to attract and retain high-quality teachers. ${ }^{17}$ In addition, there is limited access to professional development opportunities for teachers in rural schools compared with urban and suburban schools. ${ }^{18}$ Finally, there is a positive impact of technology use on mathematics learning, ${ }^{19}$ and computers are becoming an increasingly more important aspect of mathematics education, even in the early grades. However, rural schools are less likely to have adequate computer facilities, ${ }^{20}$ and while schools across the country are making use of an increasingly advanced array of educational tools available on the internet, rural students are more likely than their urban and suburban peers to either have no internet connection or have slower phone-based internet connections in their homes. ${ }^{21}$

\section{Data}

The data used for the analyses are from the Early Childhood Longitudinal Study, a multiyear study of a nationally representative sample of more than 22,000 children between 1998 and 2006. Children were surveyed two times during kindergarten, then in the spring of Grades 1, 3, 5, and 8. Teachers, parents, and school administrators were also surveyed. The analytic sample used here consists of the 15,260 public school students for whom data is available on mathematics achievement for at least one measurement occasion, school location, and family socioeconomic status. ${ }^{22}$ 


\section{E N D N O T E S}

1. National Mathematics Advisory Panel, Foundations for Success: The Final Report of the National Mathematics Advisory Panel (Washington, DC: U.S. Department of Education, 2008).

2. National Council of Teachers of Mathematics (NCTM), Principles and Standards for School Mathematics (Reston, VA: NCTM, 2000).

\section{K. Patterson, Rural Schools: Federal Expenditures and State Perspectives (Washington, DC: Council of State Governments, 2010).}

4. S. Provasnik et al., "Status of Education in Rural America," NCES 2007-040 (Washington, DC: U.S. Department of Education, National Center for Education Statistics, Institute of Education Sciences, 2007).

\section{M. S. Waters, editor, A Mathematics Educator's Introduction} to Rural Policy Issues, Monograph no. 2 (Athens: $\mathrm{OH}$ : Appalachian Collaborative Center for Learning, Assessment, and Instruction in Mathematics, 2005).

6. E. Bouck, "How Size and Setting Impact Education in Rural Schools," Rural Educator, vol. 25, no. 3 (2004): 38-42;

C. Howley, Research About Mathematics Achievement in the Rural Circumstance (Athens, OH: Ohio University, Appalachian Collaborative Center for the Study of Learning, Assessment, and Instruction in Mathematics, 2002), available at http://acclaim.coe.ohiou.edu/rc/rc_sub/pub/3_wp/ CBH_WP1.pdf).

7. The mathematics achievement measure used in this study is an Item Response Theory (IRT) measure, which estimates the number of items children would have answered correctly out of a total of 174 questions on the full mathematics assessment. This allows comparisons of mathematics achievement across grade levels.

8. The standard deviation in mathematics achievement in kindergarten is 10 points; therefore, differences in average kindergarten achievement between rural and suburban children represent approximately 20 percent of the typical deviation in scores, and differences between urban and suburban children represent 30 percent of the typical deviation in scores.

9. The standard deviation in mathematics achievement in eighth grade is now approximately 20 points. The rural-suburban average achievement difference is approximately onefourth of this deviation, while the urban-suburban difference is approximately 15 percent of the deviation. The average difference in achievement as a proportion of standard deviation has increased for rural students compared with suburban students, but it has decreased for urban students compared with suburban students.

10. We obtained fitted change trajectories by fitting multilevel models for change to the kindergarten through eighth grade mathematics achievement data. For a description of the multilevel model for change, see S.E. Graham, J.D. Singer, and J. B. Willett, "An Introduction to the Multilevel Model for Change," Handbook of Social Research Methods, edited by P. Alasuutari, L. Bickman, and J. Brannon (London: Sage, 2008).

11. The specific regions chosen for each graph are those with the largest representation of the racial-ethnic group in the data set.

12. D. Grissmer, et al., "Student Achievement and the Changing American Family," MR-488-LE (Santa Monica, CA: RAND, 1994); E. A. Hanusheck, "Assessing the Effects of School Resources on Student Performance: An Update," Educational Evaluation and Policy Analysis, vol.19, no. 2 (1997): 141-164.

13. See, for example, Pamela Davis-Keen, "The Influence of Parent Education and Family Income on Child Achievement: The Indirect Role of Parental Expectations and the Home Environment," Journal of Family Psychology, vol. 19 (2005): 294-304.

14. Among school-aged children in rural areas, 33 percent had a mother and 36 percent had a father with only a high school degree. This compares 26 and 24 percent, respectively, in cities, 25 and 24 percent, respectively, in suburban areas. See Provasnik et al., "Status of Education in Rural America."

15. Ibid.

16. Ibid.

17. L. Jimerson, “The Competitive Disadvantage: Teacher Compensation in Rural America," Policy Brief Series on Rural Education (Washington DC: Rural School and Community Trust, 2003).

18. D. Marlow and M. Cooper, The MetLife Survey of the American Teacher, Past, Present, and Future (New York: MetLife, 2008).

19. NCTM, Principles and Standards.

20. Provasnik et al., "Status of Education in Rural America."

21. S. P. Crawford, "The New Digital Divide," New York Times, Sunday Review (December 4, 2011, p. 1).

22. The definition of rural used in the Early Childhood Longitudinal Study is based on definitions used by the U.S. Census Bureau. Rural communities are defined as locations with 2,500 or fewer residents, or small towns with 25,000 or fewer residents. 


\section{A C K N O W LE D G MENTS}

The authors would like to thank Beth Mattingly, Bruce Mallory, Curt Grimm, Amy Sterndale, Robert Slavin, and Olga Cardoso for their thoughtful comments and suggestions; Barbara Ray for editorial assistance; and Laurel Lloyd for guidance throughout the process.

\section{ABOUT THE AUTHORS}

Suzanne E. Graham is an associate professor in education at the University of New Hampshire, and a faculty fellow at the Carsey Institute (suzanne.graham@unh.edu).

Lauren E. Provost is a Ph.D. student in education at the University of New Hampshire (lauren.reininger@unh.edu).

\section{$\triangle$ UNIVERSITY me of NEW HAMPSHIRE}

\section{CARSEY}

Building knowledge for families and communities

The Carsey Institute conducts policy research on vulnerable children, youth, and families and on sustainable community development. We give policy makers and practitioners timely, independent resources to effect change in their communities.

This work was supported by the Annie E. Casey Foundation, the W. K. Kellogg Foundation, and an anonymous donor.

Huddleston Hall

73 Main Street

Durham, NH 03824

$(603) 862-2821$

www.carseyinstitute.unh.edu 